\title{
Correlation between Self-Compassion and Level of Burnout among Special Educators in Bangalore, India
}

\author{
Malvika Krishnan and Madhurini Vallikad
}

\begin{abstract}
The study conducted looks into the correlation of self-compassion and level of burnout among special educators. The purpose of this study is to explore a possible relation between the two variables in order to have a better understanding of burnout among special educators. This study explores the possibility of utilizing self-compassion as a protective factor against burnout. Selfcompassion is a concept that has been borrowed from Buddhist philosophy which has found to reduce stress. This would contribute to the well-being of special educators which in turn facilitates better quality service to students with special needs. The study is focused on the special educators in Bangalore city, India. A special educator has to cater to the needs of their students with patience and individualized attention. With limitations to psychological resources, special educators experience more stress on a regular basis. There is a need to retain qualified special educators as an increasing number of special educators migrate to the general education setting. This study was conducted on 56 special educators in Bangalore through purposive and snowball sampling technique. The tools for assessment used are the Self-Compassion Scale and the Maslach Burnout Inventory- Educators Survey. A correlational study between selfcompassion, the dimensions of which are self-kindness, common humanity, mindfulness, self-judgement, over identification and isolation and the level of burnout and its dimensions- emotional exhaustion, depersonalisation and personal accomplishment, was conducted. The outcomes of this study showed that there was a significant correlation between mindfulness and personal accomplishment. Increasing one's awareness of their own experience can bring about a sense of competence in their professional life. It allows special educators to realize their contribution towards the education of their students. This can facilitate in retention of special educators in the field. It was also found that an increased feeling of isolation can influence emotional exhaustion and the level of burnout. By receiving more support from institutions as well as catering to the well-being of special educators can decrease attrition rates.
\end{abstract}

Keywords - Self-compassion, special education, burnout, retention, Bangalore, India.

\section{INTRODUCTION}

Compassion is a trait that is quite often shown to others rather than directed at oneself. People tend to be sympathetic to another person's suffering and go out of their way to help them reduce it. But neglect to extend the same compassion

Malvika Krishnan, Jain University, India Dr. Madhruini Vallikad, Jain University, India towards themselves. The idea of self-compassion initially emerged from Buddhism which encourages people to take care of themselves, thus in turn, helping them take care of others. When one is critical of oneself, they form a distinction between themself and the world. One becomes isolated and disconnected from the world[1].

In her book, Kristen Neff said " Self-esteem is the perfect alternative to the relentless pursuit of self-esteem as it provides the same protection against harsh self-criticism without the need to see ourselves as perfect beings."'[1]. One of the issues of using self-esteem as an essential measure of health is that it stems from evaluating one's own worth in the world. This is determined via comparisons and judgement by using the external environment as a reference. Therefore, one's liking towards themself is not solely based on themself, but influenced by extrinsic factors as well. Self-esteem is proven to be resistant to change[2]. Self-esteem can form a blinding shield due to which an individual would find it difficult to identify the areas in which growth and development is required. Self-compassion changes the perception of oneself and allows one to accept their own flaws or any suffering without harsh criticism which in turn can lead to the growth of self, compassion that is extended towards oneself increases the ability to perceive grievances with warmth, a feeling of connection and concern. Although research shows that individuals are primarily interested in themselves, through common experience, it is seen that individuals tend to judge themselves and are more critical of themselves than their loved ones or even strangers[3] .One question which may emerge from the concept of self-compassion is that would high levels of self-compassion lead to self-pity and self-indulgance? But being compassionate towards one's own suffering allows an individual to see their suffering as a part of the common human experience. Self-compassion is also known to reduce anxiety and neurotic perfectionism, it acts as a protective factor against anger and close-mindedness[4].

According to Neff [3]. Self-Compassion was conceptualized using three broad dimensions- self-kindness, common humanity and mindfulness. Self-kindness is the central aspect consisting of treating oneself kindly in the face of difficulties, failures or when one has made a critical error. The converse to this is self-judgement wherein an individual directs criticism towards his or her self for flaws or errors. 
The second aspect of self-compassion is common humanity which involves recognizing that one's experiences, no matter how painful, are part of the common human experience. When people fail, experience loss or rejection, are humiliated, or confront other negative events, they often feel that their experience is personal and unique when, in reality, everyone experiences problems and suffering.The converse to this is isolation, a feeling of separation from humanity and loneliness while facing loss.

The third aspect is mindfulness, when an individual takes a balanced perspective of their negative experiences and stress, allowing for better coping strategies. Conversely, overidentification takes place when the individual treats a negative instance as a catastrophe and avoids challenges for the fear of failure.

Burnout is a state of mind of behavioral, psychological and intellectual fatigue that emerges from chronic or intense occupational stress. Burnout is characterized by a negative or apathetic perceptional attitude towards one emotional state, their work environment and personal accomplishments[5]. It can be caused by longer working hours or monotonous tasks. Maslach came across this phenomenon while studying how people cope with emotional arousal at the work place. Literature written prior to the coining of this term showed similar psychological states under various names such as exhaustion reaction. Research showed that burnout occurs more commonly among practitioners of people-oriented, human-service professionals. These include fields of education, social services, medicine, the criminal justice system mental health, religion among others.

The distinction between burnout and stress can be explained with respect to time and the distinction between burnout and depression and satisfaction can be considered domain-related [6]. Chronic job stress which challenges an individual's resources can be considered burnout. The prolonged exposure to stress can cause depletion in psychological resources leading to irreversible damage. Stress is a temporary adaption process accompanied by physical and mental symptoms, burnout is a breakdown in adaptation process accompanied by chronic malfunction [7].

A study conducted on the clergymen of southeastern United States studied the correlation between clergy burnout and selfcompassion. The results of the study showed that clergymen with high self-compassion had a lower level of emotional exhaustion[8]. An experimental study on mindfulness group work in order to prevent stress and increase self-compassion. Practicing mindfulness directly influences self-compassion and is a protective factor against harsh self-judgement[9]. An investigation conducted on the migration of special educators from the field of special education to general education. The reasons were found to be lack of administrative support and the stress of teaching children with special needs[10]. A study conducted on special educators on the development of burnout over a period of five years showed that special educators did not experience impersonal or unfeeling response towards their students and felt competent in their professional life[11].

\section{METHODOLOGY}

This study aims to find a correlation between the Selfcompassion and level of burnout among special educators in Bangalore. This chapter deals with the nature of the study, the objectives, hypotheses and the procedure and tools with which this study was conducted. The aim of the study is to explore the relationship between self-compassion and level of burnout among special educators in Bangalore. The objectives of the study is to measure the self-compassion and level of burnout among special educators and to check the relation between the variables among special educators in Bangalore. A null hypothesis has been set as there have been few researches that have looked into the relationship between the two variables in an Indian setting.

There is no significant relationship between self-compassion and level of burnout among special educators in Bangalore.

The study contains a sample size of 56 special educators who are currently working in Bangalore. The sampling method used was purposive sampling and snowball sampling method. The researcher was granted permission to collect data from one special school from 15 special educators and 41 special educators participated through online forms. A brief description of the study was given to all the special educators along with consent forms. The Self-Compassion Scale developed by Kristen Neff [3] and the Maslach Burnout Inventory- Educators Survey[12]. were administered to the participants. The average time taken to complete both the tests was approximately 20 minutes. Self-compassion is a healthy acceptance of oneself, which is different from self-pity.It is a self-understanding attitude that allows oneself to be in touch with their own suffering and open oneself towards it while seeking not to be disconnected from it. It has sub-themes of self-kindness, self-judgement, common humanity, isolation, mindfulness, over-identified. It is a standardized questionnaire with 26 items that have the sub-themes of selfkindness, self-judgement, common humanity, isolation, mindfulness and over-identified. It contains six sub-themes measured on a Likert scale. The test has a good internal consistency reliability of .92 and a good test-retest reliability of .93. Burnout is defined as a psychological syndrome involving emotional exhaustion, depersonalization, and a diminished sense of personal accomplishment that occurred among various professionals who work with other people in challenging situations. It includes the dimensions of emotional exhaustion, depersonalization and personal accomplishment. The test has been validated and proven to be reliable, it has 22 items. It is measured on a 7 point scale based on frequency of occurrance.

The sociodemographic form contained details such as gender, level of qualification in the special education field, years of experience and area of focus. It was found that majority of the sample were female with a diploma in special education, with years of experience ranging from 2 years to 
over 15 years. Their area of focus was found to be specific learning difficulty, autism and attention-deficit hyperactivity disorder.

\section{RESULTS AND DisCUSSIONS}

TABLE I(A): SHOWING THE MEAN SCORES OF THE DIMENSIONS OF LEVEL OF BURNOUT OF SPECIAL EDUCATORS:

\begin{tabular}{|l|l|l|}
\hline $\begin{array}{l}\text { Dimensi } \\
\text { ons of } \\
\text { burnout }\end{array}$ & Mean scores & Standard Deviation \\
\hline $\begin{array}{l}\text { Emotion } \\
\text { al }\end{array}$ & 11.03 & 9.38 \\
$\begin{array}{l}\text { Exhausti } \\
\text { on }\end{array}$ & & \\
\hline $\begin{array}{l}\text { Deperso } \\
\text { nalizatio } \\
\text { n }\end{array}$ & 3.03 & 2.86 \\
\hline $\begin{array}{l}\text { Personal } \\
\text { Accompl } \\
\text { ishment }\end{array}$ & 37.40 & 8.37 \\
\hline
\end{tabular}

The mean score for each dimension of level of burnout is found to be 11.03 for emotional exhaustion, a low score in accordance to the scoring key of the Maslach Burnout Inventory- Educator's Survey. The sample might be protected by factors that contribute to a lower sense of emotional exhaustion such as perceived support from colleagues, familial support, a sense of purpose while teaching children with special needs. The sample also shows a low mean score of 3.03 in the dimension of depersonalization. This is in accordance to the study conducted by Frank and McKenzie wherein special educators had no impersonal feelings towards their students and do not develop an apathetic attitude towards their students. The sample shows a high mean score of 37.40 in the dimension of personal accomplishment. This was also seen in the study of Frank and McKenzie as special educators have a sense of contentment in their professional life. The results show that special educators may not feel the need to migrate to general education as long as there is perceived support from other special educators as well as a sense of contributing to the education of children with special needs.

TABLE I(B): SHOWS THE MEAN SCORES OF THE DIMENSIONS OF SELFCOMPASSION OF SPECIAL EDUCATORS:

\begin{tabular}{|l|l|l|}
\hline $\begin{array}{l}\text { Dimensions of self- } \\
\text { compassion }\end{array}$ & Mean score & $\begin{array}{l}\text { Standard } \\
\text { Deviation }\end{array}$ \\
\hline Self-Kindness & 16.05 & 3.04 \\
\hline Self-judgement & 14.07 & 3.47 \\
\hline Common Humanity & 15.58 & 6.72 \\
\hline Isolation & 11.75 & 2.56 \\
\hline Mindfulness & 15.12 & 2.84 \\
\hline Over-identification & 12.10 & 2.49 \\
\hline
\end{tabular}

The table shows the mean score of the sample on the different dimensions of self-compassion. The mean scores of the positive dimensions - self-kindness, common humanity and mindfulness is seen to be are higher than that of their negative counterparts of self-judgement, isolation and overidentification. The results show a higher level of selfcompassion among special educators. Especially in the dimension of self-kindness. This may show an understanding of the positive effect of displaying kindness to the self, especially during challenging times, while dealing with the slow academic progress of children with special needs. As evidenced by a study conducted by Newsome, Waldo and Gruzska, mindfulness increases self-compassion and is protective against harsh self-judgement. Self-judgement was found to be the highest mean score among the negative dimensions of self-compassion. If special educators were exposed to more mindfulness-based activities, it would reduce self-judgement. Common humanity appears to have the highest standard deviation value. This shows that among the sample, there are variations in the belief that flaws and mistakes are all common experiences which aids in acceptance of one's flaws.

TABLE II (A) SHOWS THE CORRELATION BETWEEN SELF-COMPASSION AND LEVEL OF BURNOUT AMONG SPECIAL EDUCATORS.

\begin{tabular}{|l|l|l|}
\hline & Self-compassion & Level of Burnout \\
\hline Self-compassion & & -0.01 \\
\cline { 2 - 3 } & & 0.94 \\
\hline Level of Burnout & -0.01 & 1 \\
\hline
\end{tabular}

Correlation is not significant.

According to Table 4.3, there is no significant correlation between self-compassion and level of burnout $(r=-0.10)$. The objective of the study is to investigate the relationship between self-compassion and burnout among special educators. Thus, the hypothesis stating that 'There is no significant relation between self-compassion and burnout ' is accepted. The possible reasons for these findings could be due to the influence of midfulness, which was found to high among the sample. Mindfulness can mediate the effect of stress as it allows negative experiences to be viewed from a certain level of awareness.It can also bring to attention the more positive experiences of a special educator while teaching children with special needs. As self-compassion has been found to reduce stress and a sense of isolation. Research shows that an increase in perceived social support allows special educators to share feelings of failure. Bringing about a sense of acceptance of flaws can help special educators accept slow academic progress of their students without attributing it to their personal efforts. This can be explained further with the help of the dimensions within the two variables. 
TABLE II(B): SHOWS THE CORRELATION OF THE DIMENSIONS OF SELFCOMPASSION AND LEVEL OF BURNOUT AMONG SPECIAL EDUCATORS.

\begin{tabular}{|c|c|c|c|c|}
\hline & $\begin{array}{l}\text { Emotional } \\
\text { Exhaustion }\end{array}$ & $\begin{array}{l}\text { Depersonali } \\
\text { zation }\end{array}$ & $\begin{array}{l}\text { Personal } \\
\text { Accomplish } \\
\text { ment }\end{array}$ & $\begin{array}{l}\text { Total } \\
\text { Burnou } \\
\mathrm{t}\end{array}$ \\
\hline $\begin{array}{l}\text { Self- } \\
\text { kindness }\end{array}$ & $\begin{array}{l}-0.08 \\
0.54\end{array}$ & $\begin{array}{l}0.02 \\
0.83\end{array}$ & $\begin{array}{l}0.35^{* *} \\
0.00\end{array}$ & $\begin{array}{l}0.20 \\
0.12\end{array}$ \\
\hline $\begin{array}{l}\text { Self- } \\
\text { judgeme } \\
\text { nt }\end{array}$ & $\begin{array}{l}-0.31 \\
0.01\end{array}$ & $\begin{array}{l}0.10 \\
0.43\end{array}$ & $\begin{array}{l}-0.05 \\
0.68\end{array}$ & $\begin{array}{l}-0.26 \\
0.05\end{array}$ \\
\hline $\begin{array}{l}\text { Common } \\
\text { Humanit } \\
\text { y }\end{array}$ & $\begin{array}{l}-0.10 \\
0.43\end{array}$ & $\begin{array}{l}0.07 \\
0.59\end{array}$ & $\begin{array}{l}0.23 \\
0.07\end{array}$ & $\begin{array}{l}0.10 \\
0.44\end{array}$ \\
\hline Isolation & $\begin{array}{l}-0.35^{* *} \\
0.00\end{array}$ & $\begin{array}{l}-0.02 \\
0.84\end{array}$ & $\begin{array}{l}-0.09 \\
0.49\end{array}$ & $\begin{array}{l}-.35^{* *} \\
0.00\end{array}$ \\
\hline $\begin{array}{l}\text { Mindfuln } \\
\text { ess }\end{array}$ & $\begin{array}{l}-0.19 \\
0.14\end{array}$ & $\begin{array}{l}-0.15 \\
0.25\end{array}$ & $\begin{array}{l}0.52 * * \\
0.00\end{array}$ & $\begin{array}{l}0.19 \\
0.15\end{array}$ \\
\hline $\begin{array}{l}\text { Overiden } \\
\text { tification }\end{array}$ & $\begin{array}{l}-0.29 \\
0.02\end{array}$ & $\begin{array}{l}-0.12 \\
0.37\end{array}$ & $\begin{array}{l}0.26 \\
0.04\end{array}$ & -0.06 \\
\hline $\begin{array}{l}\text { Self- } \\
\text { compassi } \\
\text { on }\end{array}$ & $\begin{array}{l}-0.35^{* *} \\
0.00\end{array}$ & $\begin{array}{l}0.01 \\
0.09\end{array}$ & $\begin{array}{l}0.35^{* * *} \\
0.00\end{array}$ & $\begin{array}{l}-0.01 \\
0.94\end{array}$ \\
\hline
\end{tabular}

*Correlation is significant at 0.05 level. ** Correlation is significant at 0.01 level

A highly significant positive correlation $(r=0.35)$ was found between self-kindness and personal accomplishment. The characteristic of self-kindness allows for acknowledgment of accomplishments, while attributing them to personal efforts and resources. Thus, when one comes across challenges, by showing kindness and encouragement towards the self, chances of overcoming these challenges are higher, hence there is an increase in a feeling of personal accomplishment. Thus, through any slow academic progress of their student, a special educator who provides, not only their student with positive encouraging talk, but with themselves as well, tend to feel a heightened sense of personal accomplishment.

There is a significant negative correlation between selfjudgement and emotional exhaustion as well as a highly significant negative correlation $(r=-0.35)$ between isolation and emotional exhaustion. The research findings of a study conducted by Barnard and Curry showed that clergymen with a greater sense of self-compassion experienced lower emotional exhaustion. Both these negative dimensions of self-compassion influence emotional exhaustion as self-directed criticism and anger has an adverse effect on one's emotional resources, hence leading to exhaustion. It takes more effort to orient oneself towards personal growth when their energy goes into self- deprecation, rather than when is accepting of his or her flaws. In relation to isolation and emotional exhaustion, in the absence of perceived social support and the perception of being cut off from the rest of the world, a feeling of emotional exhaustion increases. In the context of special educators, when one is faced by a challenge at work place and believes they do not have the support required from their colleagues or the authorities of their organization, they would have higher emotional exhaustion. Additionally, if they believed that they were alone in their suffering and none of their colleagues seem to face similar challenges, isolation increases and leads to a feeling of emotional exhaustion.

A highly significant negative correlation $(r=-0.35)$ was found between isolation and burnout. The results imply that burnout can reduce when there is a sense of connection with peers and when one believes that he or she is not alone in their suffering. This could include social support from other special educators within the field as well as support from the parents of the child with special needs.

A highly significant positive correlation $(r=0.52)$ was found between mindfulness and personal accomplishment. The implications of this relation is that when one is aware of their emotions from a balanced point of view, they tend to experience a higher sense of personal accomplishment which facilitates personal growth and development as well. This correlation was found to be the highest among the dimensions. This could imply that mindfulness could have a great influence over a special educator's sense of acheivement. This could possibly be a significant reason that they choose to continue working in this profession.

Over-identification tends to lead to rumination taking up valuable emotional resources. This can eventually turn into emotional exhaustion. When one's focus goes to the negative aspect of a situation, it becomes more difficult to realize one's personal accomplishments and results in feelings of inadequacy in the work place. A highly significant negative correlation $(\mathrm{r}=-0.35)$ was found between self-compassion and emotional exhaustion along with a highly significant positive correlation $(\mathrm{r}=0.35)$ between self-compassion and personal accomplishment. Self-compassion as a whole can reduce the detrimental effects of emotional exhaustion in special educators and enhance their feelings of success thus possibly motivating them to remain in the field of special education.

The study has scope to explore the trait of self-compassion as a protective factor against the stress experienced in humanservice oriented professions. As explained by Neff, selfcompassion is not a fixed trait, it can be developed, which would further increase the well-being of an individual without depending on external validation.

\section{CONCLUSION}

The study has found that there is no significant correlation between self-compassion and level of burnout among special educators. Thus, the hypothesis of this study was found to be validated. Further analysis of the dimensions of selfcompassion and level of burnout shows the possible influence of mindfulness and self-kindness on the sense of personal accomplishment in the field of special education. Thus, the act 
of rewarding oneself with kind judgement and bringing about an awareness of one's achievements can enhance a sense of purpose and value to their contribution as special educators. This can mediate the effect of stress on special educators and reduce levels of burnout.This study can also contribute some knowledge towards the well-being of special educators as well as influence their retention in this field of education.

\section{ACKNOWLEDGMENT}

The author, Malvika Krishnan would like to thank Dr. Madhurini Vallikad, Co-coordinator of Department of Psychology for her constant support and invaluable input. A special thanks to the special schools that have permitted the author to collect data from their special educators.

\section{REFERENCES}

[1] K.,Neff, Self- Compassion, Hodder and Stoughton, Great Britain, 2013.

[2] W.B, Swann, The trouble with change: self-verification and allegiance to the self in Psychological Science8 (3), 1997, 177-180.

[3] K.D, Neff, Development and validation of a scale to measure selfcompassion in Self and Identity, 2, 2003, 223-250.

[4] K.D Neff, McGhee, Self-compassion and psychological resilience among adolescents and young adults in Self and Identity, 9, 2010, 225240.

[5] C. Maslach, S.E Jackson and M.P Leiter. Maslach Burnout Inventory (3), 1986.

[6] W.B Schaufeli, M.P Leiter, , C. Maslach. Burnout: 35 years of research and practice. 2008, 204-220.

[7] P.L Brill, The need for an operational definition of burnout in Family and Community Health 6 (4), 1984, 12-24.

[8] K.L Barnard, F.J Curry Relationship of clergy burnout to selfcompassion and other personality dimensions, Pastoral Psych, 61,2012, 149-163. https://doi.org/10.1007/s11089-011-0377-0

[9] S. Newsome, M. Waldo,C. Gruszka. Mindfulness group work:Preventing stress and decreasing self-compassion among helping professionals in training in Journal for Specialists in Groupwork. 2012.

[10] B.S Billingsly, H.L Cross. Teacher's decision to transfer from special to general education in The Journal of Special Education, 24 (4) 1991, 496-511.

[11] A. R Frank, R McKenzie. The development of burnout among special educators. 1993.

[12] Copyright $\odot 1986$ Christina Maslach, Susan E. Jacksonand Richard L. Schwab. All rights reserves in all media. Published by Mind Garden Inc.

[13] B.A Allen and L.M Leary. Self-compassion, stress and coping in Social and Personality Psychology. 2010.

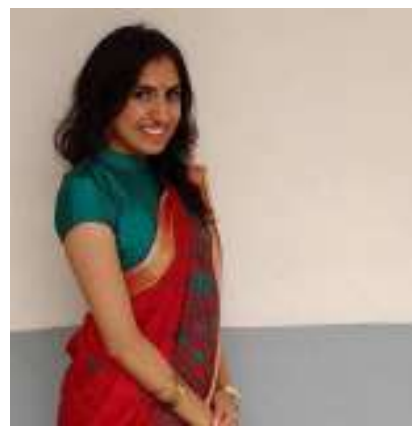

"Acknowledge the existence of flaws, all the while allowing compassion to elevate stress. This facilitates self-growth to help one become their optimum professional self”.

Malvika Krishnan.

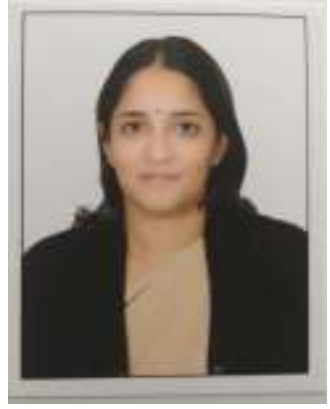

community populations.
Dr Madhurini Vallikad is a clinical psychologist and Assistant professor at Jain University. She has completed her M. Phil and PhD at the National Institute of Mental Health and NeuroSciences, ( NIMHANS), Bangalore. She is interested in research and psychotherapy with stress and burnout, family and marriage and the applications of positive psychology in clinical and 